\title{
Assessing and enhancing the impact potential of marketing articles
}

\author{
Elina Jaakkola ${ }^{1}$. Stephen L. Vargo ${ }^{2}$
}

Received: 4 October 2021 / Accepted: 14 November 2021 / Published online: 2 December 2021

(c) The Author(s) 2021

\begin{abstract}
Although the impact of marketing is a recognized priority, current academic practices do not fully support this goal. A research manuscript's likely influence is difficult to evaluate prior to publication, and audiences differ in their understandings of what "impact" means. This article develops a set of criteria for assessing and enhancing a publication's impact potential. An article is argued to have greater influence if it changes many stakeholders' understandings or behaviors on a relevant matter; and makes its message accessible by offering simple and clear findings and translating them into actionable implications. These drivers are operationalized as a checklist of criteria for authors, reviewers, and research supervisors who wish to evaluate and enhance a manuscript's potential impact. This article invites scholars to further develop and promote these criteria and to participate in establishing impact evaluation as an institutionalized practice within marketing academia.
\end{abstract}

Keywords Impact $\cdot$ Publishing $\cdot$ Relevance $\cdot$ Writing $\cdot$ Citations

\section{Introduction}

For decades, there has been a lingering concern that the impact of marketing is declining, both as a discipline and in the board room (e.g., Clark et al., 2014; Lehmann et al., 2011; Reibstein et al., 2009). In academia, one might argue that "being impactful" has become a mantra: citations are counted for promotion applications; scholars' reputation is increasingly affected by their h-index; external funding bodies tend to make decisions based on a research project's expected business or societal impact; and business school accreditation boards and university ranking systems treat impact as a key standard (e.g., Birkinshaw et al., 2016). As a result, scholars engage in ongoing discussion of how marketing research might be made more relevant, important, and useful (e.g., Bolton, 2020; Kohli \& Haenlein, 2021; MacInnis et al., 2020; Stremersch, 2021), so acknowledging that the future of marketing as a science will ultimately be defined by its impact.

Elina Jaakkola

elina.jaakkola@utu.fi

Stephen L. Vargo

svargo@hawaii.edu

1 Turku School of Economics, University of Turku, Turku, Finland

2 University of Hawai'i, Honolulu, USA
At the same time, many scholars have noted that current academic practices fail to optimally support impactful research (e.g., Clark et al., 2014; Key et al., 2020; Reibstein et al., 2009). As the discipline of marketing grows and matures, standards continue to rise for publishing and tenure, prompting a methods focus as opposed to an impact focus (Houston, 2019). Researchers tend to remain stuck in disciplinary or philosophical silos which means that they continue to speak to narrow, predefined audiences (MacInnis et al., 2020). Many journal editors have called for research that breaks with existing institutions-for example, more conceptual work (e.g., Clark et al., 2014; MacInnis, 2011; Yadav, 2010); more relevant and important research topics (Kohli \& Haenlein, 2021; Reibstein et al., 2009); and more boundary-challenging or interdisciplinary research (Moorman et al., 2018, 2019; Yadav, 2018).

However, in a persisting disconnect between the ideal of impact and grassroots practice, both authors and reviewers continue to prioritize methodological rigor over impact potential. While authors often go to great lengths to explicate how their work adds to existing knowledge, the likely influence of their findings on various stakeholders is seldom comprehensively discussed. One possible reason for this is that the future impact of a given article is difficult to evaluate prior to publication. Meanwhile, there are well established quality guidelines for rigor, including validity, reliability and objectivity; and failure to articulate measures to ensure research trustworthiness often results in manuscript rejection. In the absence of any equivalent criteria, 
evaluating impact remains largely intuitive. This lack of concrete actionable tools for evaluating and articulating the potential impact of a research manuscript hinders its adoption as a guiding norm for academic marketing research.

In this article, we contend that the promotion of more impactful marketing research will depend on developing and institutionalizing a set of criteria for assessing and enhancing a study's potential impact. Our aim here is to take a first step toward that goal. At present, authors can access advice on how to enhance particular impact-related aspects of a manuscript - for example, by crafting interesting and relevant research questions (e.g., Kohli \& Haenlein, 2021; Lange \& Pfarrer, 2017; Shugan, 2003) or developing theoretical contributions (e.g., MacInnis, 2011; Makadok et al., 2018) - but there is as yet no comprehensive set of criteria for evaluating the diverse drivers of impact. While one can argue that prestigious journals will not accept an article that makes no significant contribution to the literature, many published articles have little impact, at least in terms of their citation count. In short, while an article's contribution is undoubtedly one element of impact, the two are not identical.

To be useful, a set of impact criteria should operationalize and integrate the key factors that can be said to drive the influence of a study on various stakeholders, and be observable in a research publication such as a journal manuscript of an academic thesis. As well as highlighting the importance of impact, the articulation of such criteria would support the assessment and enhancement of a research manuscript's potential impact and would ultimately facilitate the establishment of such measures as an institutionalized practice in marketing academia.

We start by reviewing existing viewpoints on impact in marketing research to define what this means as a goal for academic publication. Next, we identify drivers of impact potential that should inform the development of explicit criteria. We identified those drivers by analyzing research articles and editorials that focus on impact and relevance, as well as by reflecting on our own experiences as editors, reviewers, and authors for various journals. As the article's main outcome, we specify an integrative set of criteria that can be used to evaluate and enhance the likely impact of articles submitted for publication.

\section{Defining impact as a goal for academic publication}

In operationalizing impact, one underlying challenge is the multifaceted nature of that concept and how interpretations of the term differ across users and audiences (Penfield et al., 2014). For that reason, scholarly impact must be more clearly defined in order to develop effective ways of inspiring and achieving it (Aguinis et al., 2014). Current scholarly and policy research reveal diverse perspectives on the nature of impact, ranging from a publication's citation count to a research program's societal benefits (see Aguinis et al., 2014; see also Table 1). Following Reale et al. (2018, p. 298), we define research impact here as " $a$ change that research outcomes produce upon academic activities, the economy, and society at large."

As outlined in Table 1, marketing scholars typically address impact from three complementary perspectives. The first of these focuses on scientific impact in terms of the influence that particular publications, authors, journals, or streams have within marketing, or the influence of marketing research on other business sciences, typically measured by citations (Aguinis et al., 2014; Baumgartner \& Pieters, 2003). The second approach focuses on business impact: how research informs marketing practice (e.g., Roberts et al., 2014) or how marketing contributes to firm performance and decision making (e.g., Krasnikov \& Jayachandran, 2008). Finally, the third perspective focuses on the societal impact of marketing research: the effect of scholarly output on advancing wellbeing (e.g., Blocker et al., 2013) or the use of that knowledge for public or societal decision making (e.g., Davis \& Ozanne, 2019). In that context, possible audiences for marketing research include educators, funding agencies, media, public policymakers, and regulators (Shugan, 2003).

As Table 1 illustrates, current perspectives on impact within the discipline of marketing address different domains of change, operationalizing impact as the diffusion and/or influence of academic output among stakeholders within these domains. Accordingly, an academic study's impact is arguably greater when it engages a broader range of stakeholders and triggers more extensive change in their thinking or actions.

\section{Drivers of impact}

Scholars have discussed myriad factors that may affect research impact, not all of which can be assessed at the level of academic publication (Hauser, 2017; Sternberg \& Gordeeva, 1996). These factors range from the promotion of published articles to academic practices pertaining to broader science policy, such as industry-academia collaboration (e.g., Hauser, 2017; Kohli \& Haenlein, 2021; Lindgreen et al., 2020). As the goal of this article is to develop guidelines for assessing a paper's impact potential, we confine our attention here to drivers that are observable within a manuscript. For that reason, some measures such as the dissemination of research findings through seminar presentations or social media (e.g., Lindgreen et al., 2020) or efforts to influence managerial and public policy decision making through marketing institutions and consultancy (Bolton, 2020) are beyond our scope here. 
Table 1 Perspectives on the impact of marketing

\begin{tabular}{|c|c|c|}
\hline Domain of impact & Typical proxies for impact & Examples \\
\hline \multicolumn{3}{|l|}{ Scientific impact } \\
\hline Impact within the marketing discipline & $\begin{array}{l}\text { - Citations per article or scholar } \\
\text { - Citation patterns within and across marketing } \\
\text { research streams }\end{array}$ & $\begin{array}{l}\text { Hoffman and Holbrook (1993) } \\
\text { Baumgartner and Pieters (2003) } \\
\text { Backhaus et al. (2011) }\end{array}$ \\
\hline Impact within disciplines other than marketing & $\begin{array}{l}\text { - "Intellectual balance of trade," citation flows } \\
\text { across disciplines } \\
\text { - Cross-disciplinary borrowing of theories }\end{array}$ & $\begin{array}{l}\text { Day (1992) } \\
\text { Clark et al. (2014) } \\
\text { Nelson et al. (2017) }\end{array}$ \\
\hline \multicolumn{3}{|l|}{ Business impact } \\
\hline Impact of marketing research on marketing practice & $\begin{array}{l}\text { - Diffusion and influence of marketing science } \\
\text { models within firms } \\
\text { - Use of research to solve practical marketing } \\
\text { problems }\end{array}$ & $\begin{array}{l}\text { Leeflang and Wittink (2000) } \\
\text { Lilien et al. (2013) } \\
\text { Roberts et al. (2014) }\end{array}$ \\
\hline Impact of marketing on firm performance & $\begin{array}{l}\text { - Impact of marketing on organizational decision } \\
\text { making } \\
\text { - Impact of firm marketing investment or capability } \\
\text { on profitability and shareholder value }\end{array}$ & $\begin{array}{l}\text { Krasnikov and Jayachandran (2008) } \\
\text { Srinivasan and Hanssens (2009) } \\
\text { Nath and Mahajan (2011) }\end{array}$ \\
\hline \multicolumn{3}{|l|}{ Societal impact } \\
\hline $\begin{array}{l}\text { Impact of marketing research on consumer and } \\
\text { societal wellbeing }\end{array}$ & $\begin{array}{l}\text { - Societal benefits of research } \\
\text { - Use of research to advance sustainable marketing } \\
\text { initiatives } \\
\text { - Use of research knowledge to improve the condi- } \\
\text { tions of the underprivileged }\end{array}$ & $\begin{array}{l}\text { Bolton (2020) } \\
\text { Antonetti and Maklan (2014) } \\
\text { Blocker et al. (2013) }\end{array}$ \\
\hline $\begin{array}{l}\text { Impact of marketing research on public and societal } \\
\text { decision-making }\end{array}$ & $\begin{array}{l}\text { - Societal awareness of scholarly output } \\
\text { - Influence of research on policy making }\end{array}$ & $\begin{array}{l}\text { Davis and Ozanne (2019) } \\
\text { Aspara and Tikkanen (2017) }\end{array}$ \\
\hline
\end{tabular}

Based on our reading of the literature, our reflections on articles that have come to influence marketing thought over time, and our own experiences as editors, reviewers, and authors, we propose that there are two key drivers of impact (Fig. 1). The first of these is change potential, reflecting the common view of impact as the change that research induces in a range of stakeholders (Morton, 2015; Penfield et al., 2014; Reale et al., 2018; Stremersch, 2021). The second driver is accessibility: how effectively a publication communicates its message to the intended audience. Many scholars have noted that insightful ideas may go unnoticed if obscured by complicated communication (e.g., Stremersch

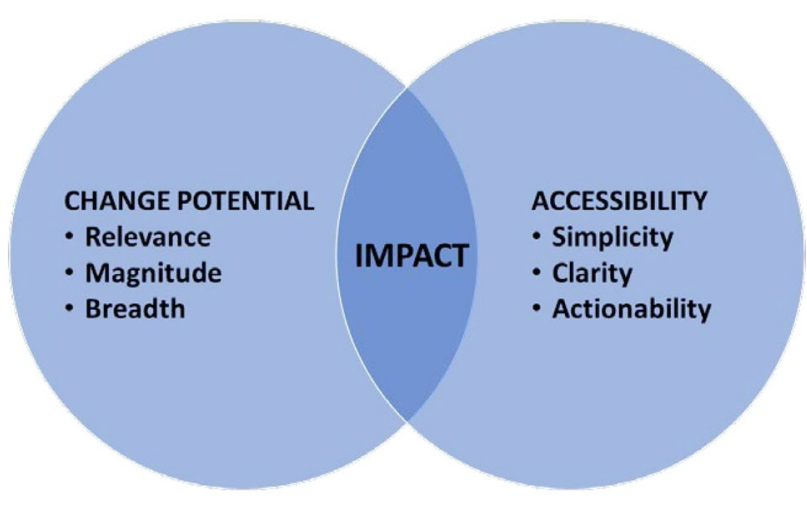

Fig. 1 Drivers of publication impact potential et al., 2007; Houston, 2019; Warren et al., 2021), and our own experiences of the review processes of various journals confirm this view.

According to the proposed framework, a publication's impact potential will be high if it is likely to promote significant change in important stakeholders' understanding or behavior and if a simple explanation is clearly translated into actionable implications to make the message accessible. These elements are discussed in more detail below.

\section{Change potential}

Many authors consider the research question to be the primary driver of impact (Houston, 2019; Stremersch, 2021), emphasizing that impactful research promotes change in matters that are relevant (e.g. Bolton, 2020; Kohli \& Haenlein, 2021). Scholars have suggested alternative pathways for identifying relevant and important research topics. One approach is to address a topic that is likely to advance theory within a given research domain by solving a puzzle, paradox, or tension that hinders its development or by studying emerging phenomena that require substantial theoretical advances to understand them (Houston, 2019; Li et al., 2021; Smith, 2003; Yadav, 2018). Smith (2003) suggested that impactful research topics might for example initiate new domains of inquiry by introducing novel concepts, resolving inconsistent findings, or intervening in accepted causal models to posit new explanations. Others 
have argued that relevant research problems often relate to "big questions" such as climate change, which pose challenges for researchers because they tend to be broad and ill-structured, and lack clear criteria or algorithms for solving them (Key et al., 2020). Another frequently suggested approach is to identify significant problems faced by marketing stakeholders (Kohli \& Haenlein, 2021; MacInnis et al., 2020; Moorman et al., 2019). For example, Zeithaml et al. (2020) suggested exploring marketing phenomena from the perspective of those most closely involved - firms, consumers, and managers-in order to focus on key issues for marketing practice by capturing relevant issues in real-world settings. Collaboration with practitioners and immersion in industry or related contexts can help researchers to pinpoint important problems that need to be solved (Bolton, 2020; Stremersch, 2021).

Another dimension of research impact is magnitude of change - that is, how radically the research might change current understanding or behavior (Kohli \& Haenlein, 2021). According to Stremersch (2021), impactful research potentially causes someone to act or think differently-for example, by influencing stakeholder decision making, prompting the adoption of different methods, changing opinions or objectives, or promoting a new approach to problem solving (Morton, 2015; Shugan, 2003). Analyses indicate that impactful research articles often explain existing phenomena better than previous work (Sternberg \& Gordeeva, 1996) or challenge the disciplinary status quo (Li et al., 2021). Tellis (2017) noted that arguments refuting current knowledge are especially impactful. In a similar vein, Smith (2003) contended that challenging taken-for-granted practices and assumptions makes a study interesting. More generally, challenging the premises on which a theory, domain, concept, or method relies can induce significant change-for example, by testing a research stream's key assumptions or probing the external validity of what is considered true (e.g., Hauser, 2017; Makadok et al., 2018; Smith, 2003).

Problematization beyond incremental gap-spotting is another widely recommended method of identifying and formulating research questions that can potentially induce major change within a given field (Alvesson \& Sandberg, 2011). In the present context, problematization means questioning the assumptions underpinning existing theory in some significant way to identify new and inspiring points of departure for theory development or paradigm shift (Sandberg \& Alvesson, 2011). In practical terms, this means articulating a compelling complication in something assumed to be true in the field and arguing for the significance of that complication (Lange \& Pfarrer, 2017). According to Sandberg and Alvesson (2011), research that merely identifies gaps in the existing literature relies on and even strengthens prevailing assumptions because that gap falls within the confines of existing theory. Research inspired by the existing academic literature in one's silo is likely to perpetuate ignorance of emergent phenomena pertinent to marketplace stakeholders and academics in other disciplines (MacInnis et al., 2020; Yadav, 2018). Sandberg and Alvesson (2011) argued that gap-spotting studies are inherently limited by their aim of adding to the existing literature rather than challenging it; the smaller the addition, the smaller the change induced.

A third issue is breadth of change: the extent of the audience whose understanding or behavior might be affected by the research findings. According to Kohli and Haenlein (2021), an issue that affects a large number of stakeholders is arguably more important than one that affects only a few; in the present context, potential audiences include managers, public policy makers, consumers, academics, consultants, and societal groups. Smith (2003, p. 319) refers to Zaltman's suggestion that an interesting idea is one that, if true, would require a large number of people to substantially change their beliefs or behaviors. Bolton (2020) highlights that consideration of domain(s) and stakeholders that may participate in and benefit from a study is an important part of responsible and impactful research, and provides an elaborate checklist for identifying relevant stakeholders for marketing research.

\section{Accessibility}

As the second key driver of impact, accessibility refers to how a publication's message is communicated. We focus here on three elements of accessibility: simplicity, clarity, and actionability (see Fig. 1). Many scholars have emphasized that simplicity is central to the impact of theoretical explanation. According to Tellis (2017, p. 4), "A good theory is a simple explanation of a phenomenon. The best theory is the simplest explanation for a wide set of phenomena"; or as Einstein expressed it, "The grand aim of all science is to cover the greatest number of empirical facts by logical deduction from the smallest number of hypotheses or axioms" (cited in Barnett, 2005). The same basic idea is also captured by Occam's Razor: that the best explanation for a given purpose is the simplest one-or more precisely, "entities [assumptions, foundations] should not be multiplied beyond necessity."

Contrary to these well established principles, marketing models and frameworks and associated manuscripts tend toward increasing complexity, arguably for two reasons. First, there is a tendency to draw on multiple theoretical frameworks or models to address the research objective but to inadequately reconcile them-i.e., reduce them to a set of common concepts-resulting in unnecessarily complex "Frankenstein models" (Vargo \& Koskela-Huotari, 2020). The second problem is perhaps an unintended consequence of increasingly sophisticated methodological approaches such as structural equation modeling, which allow, if not encourage modelers to incorporate an ever-increasing 
number of variables. In many cases, these are likely to be related issues.

Clarity is another important element of accessibility and impact. Several authors have noted that, over time, marketing articles have become increasingly complex and difficult to read because of how they use language (e.g., Brown et al., 2005; Key et al., 2020). In this regard, Warren et al. (2021) referred to the "curse of knowledge," as researchers' familiarity with their own field prompts them to adopt a more abstract, technical, and passive writing style that makes the message more difficult to understand. This in turn hampers impact because a text that obscures insights rather than illuminating them is likely to be ignored (Houston, 2019). In short, when the intended message is not understood, change will not occur.

One method for assessing clarity is quantitative assessment of relative sentence and word length, as in the Gunning (1952) Fog Index and the Flesch (1948) index of Reading Ease. Noting that the quality of writing improves with brevity, Tellis (2017) recommends shorter sentences, trimming of redundant phrases, and streamlining of arguments to produce articles that are short, forceful, and idea-packed. However, studies of the correlation between these variables and impact (measured as citation count) have produced mixed results. Warren et al. (2021) argued that this is because readability is not the same as clarity, which is more adequately captured as use of (1) concrete language, (2) concrete examples, (3) common words, and (4) active voice. They found these qualities to be associated with higher degrees of understanding and impact as measured by citation counts. In short, other things being equal, simpler is better.

Previous research indicates that an accessible writing style is especially important for engaging nonacademic audiences (Stremersch et al., 2007). Simple and powerful ideas, straightforward methods, and clear writing can heighten the subject matter's appeal for relevant stakeholders such as academics in other fields, business practitioners, the media, policy makers, and the general public (MacInnis et al., 2020). The language used is also likely to affect uptake of the topic among popular writers (Gonsalves et al., 2021). Journalists, consultants, and other professional service providers typically play a brokering role between academia and practice, offering a valuable conduit for disseminating research findings (Roberts et al., 2014). However, unclear writing may discourage these important middlemen or may promote a "telephone game" effect, where journalists and consultants misinterpret the research and transmit misleading messages to a wider audience.

Another accessibility-enhancing element is the extent to which research findings are actionable. Researchers can optimize their study's change potential by translating their findings into concrete guidance, action points, or tools for practitioners or other researchers. Identifying useful research implications to guide future studies can also enhance an article's impact (Sternberg \& Gordeeva, 1996)—for example, by highlighting novel research questions implicit in the findings (MacInnis, 2011) and explaining how the findings could or should be used, and by whom.

Outlining managerial and societal implications is obviously another important means of increasing a study's practical impact. In a journal article, a practical implications section offers space for translating conceptual findings into a practical format. In their analysis of most-cited businessto-business marketing articles, Baraldi et al. (2014) found that articles with a dedicated practical implications section offered more actionable implications than those distributing them throughout the article. In the latter case, implications were often abstract, non-normative, and too complicated or trivial, using language that was excessively scientific (Baraldi et al., 2014), again confirming the importance of switching language and presentation when addressing managers.

Key et al. (2020, p. 164) argued that rather than creating "parallel journal universes (jargon-academic and translatedpractitioner)," rigorous article writing should altogether avoid using impenetrable language that may alienate practitioners. However, scientific concepts are the means through which researchers arrive at findings that should in turn render implications for a wider audience beyond academia. Translation thus refers to more than language, requiring the researcher to explain why and how their study is relevant to a particular phenomenon or stakeholder group, what problems the study findings can solve, and how they might change how people think and behave (cf. Shugan, 2003).

\section{Assessing and enhancing impact potential: Tentative criteria}

Table 2 condenses the above drivers into a tentative set of criteria for assessing and enhancing a publication's impact potential. While this list is not exhaustive, it serves as a point of departure for a more robust evaluation scheme similar to those used to evaluate the trustworthiness of empirical research.

These criteria relate to the identified drivers of enhanced impact for an academic publication. The key driver is change potential, referring to the relevance, magnitude, and breadth of change that the research is likely to trigger. Authors can use the checklist in Table 2 to guide their choice of research topic and to argue for the impact potential of their research. Similarly, reviewers can look for these indicators when evaluating a manuscript. As the interest value of any research is audience-relative (Shugan, 2003), an article should clearly identify its intended audience and the scholarly, business, 
Table 2 Criteria for publication impact potential

\begin{tabular}{|c|c|c|}
\hline Impact driver & Key criteria & Assessment and enhancement of impact potential \\
\hline \multirow[t]{3}{*}{ Change potential } & Relevance of change & $\begin{array}{l}\text { - Documenting the pervasiveness of the research phenomenon } \\
\text { - Explicating what and whose problem the study resolves } \\
\text { - Explaining what makes the problem ill-structured } \\
\text { - Explaining what general market or societal phenomenon the study relates to and how }\end{array}$ \\
\hline & Magnitude of change & $\begin{array}{l}\text { - Developing the research question through problematizing rather than incremental gap- } \\
\text { spotting } \\
\text { - Explaining why the idea or research question is controversial } \\
\text { - Articulating the boundary-breaking nature of the study }\end{array}$ \\
\hline & Breadth of change & $\begin{array}{l}\text { - Explicating the intended audience of the article and the discussion to which it contributes } \\
\text { - Articulating the study's meaning and importance for different stakeholders } \\
\text { - Indicating the primary stakeholder groups who may be affected by the findings }\end{array}$ \\
\hline \multirow[t]{3}{*}{ Accessibility } & Simplicity & $\begin{array}{l}\text { - Providing the simplest explanation for a given purpose } \\
\text { - Reconciling theoretical frameworks to avoid cumbersome "Frankenstein models" } \\
\text { - Crafting hip-pocket takeaway or power expressions to capture the study's main points in } \\
\text { parsimonious form } \\
\text { - Ensuring adequate length-contribution ratio }\end{array}$ \\
\hline & Clarity of writing & $\begin{array}{l}\text { - Using short sentences and streamlined arguments } \\
\text { - Avoiding technical language and academic jargon } \\
\text { - Avoiding passive voice } \\
\text { - Ensuring coherent use of labels for concepts } \\
\text { - Using examples familiar to the broader audience } \\
\text { - Using the voice of external audiences to describe the phenomenon and its relevance-for } \\
\text { example, quotes from target audiences, popular press, or trade association releases }\end{array}$ \\
\hline & Actionability of implications & $\begin{array}{l}\text { - Articulating how the study's findings can be used in future research } \\
\text { - Offering tools or guidelines for particular research streams or domains } \\
\text { - Explicating which other research domains or disciplines could make use of the findings and } \\
\text { how } \\
\text { - Explicating how the behaviors, actions or beliefs of various stakeholders should be changed } \\
\text { by the study } \\
\text { - Making the study's underlying assumptions visible to readers who are unfamiliar with the } \\
\text { domain }\end{array}$ \\
\hline
\end{tabular}

or societal discussion to which it contributes. The article's arguments and claims can then be evaluated in relation to existing knowledge within that discussion or domain. To signal high impact potential, a publication should establish convincingly the need for significant changes of practice for a wide audience. The evaluator has some discretion in assessing how these criteria are to be applied; in some cases, the research may be considered impactful when the topic is highly relevant for a small number of key stakeholders. On the other hand, influencing a higher number of stakeholders may not be considered impactful if the change potential relates to a matter of little relevance (cf. Kohli \& Haenlein, 2021).

The proposed set of criteria also addresses a publication's accessibility. We contend that even relevant research may fail to achieve sufficient impact if it does not communicate its message in a simple, clear, and actionable manner. Spelling out the study's key findings and implications as simply as possible makes the takeaways more accessible for the reader. Authors can convey their key message using hippocket takeaways or power expressions. The former is a metaphor for ultimate parsimony; by capturing and condensing the essence of a theory or framework in a conceptual or graphical space that is sufficiently compact to be transported in a metaphorical "hip pocket," authors make it easier for the reader to understand and adopt. Perhaps the ultimate hip pocket takeaway is " $\mathrm{e}=\mathrm{mc}^{2}$ "; examples from marketing include models that capture the theoretical narrative of service-dominant logic in one simple figure (see Fig. 1 in Vargo \& Lusch, 2016) or conceptualize the nomological network of market orientation (see Fig. 1 in Kohli \& Jaworski, 1990).

"Power expressions" are sentences that crystallize the nature, impact, or relation between constructs, types, categories, or processes, as well as any key finding or argument, by catching the reader's eye and making it easy to grasp the article's main points. Many highly cited articles have achieved that status by virtue of one or two especially powerful, usable, and understandable expressions. For example, Brodie et al. (2011) presented five propositions to characterize customer engagement, one of which so powerfully captured the concept's emergence and nature that it subsequently became the most frequently cited definition of engagement. However, power expressions should not be regarded as a cheap gimmick to attract citations; rather, they 
curate and capture a study's main points in a condensed and simple form. Although authors are best placed to crystallize the essence of their research, this work is too often left to the reader.

Authors and reviewers should also pay attention to clarity, as incoherent storytelling, complex language, and academic jargon create noise that can drown out an article's message, causing the reader to disengage. In addition to the criteria in Table 2, authors can employ more detailed methods to test the clarity of their writing, such as the Writing Clarity Calculator developed by Warren et al. (2021) based on their study published in the Journal of Marketing (see also http:// writingclaritycalculator.com/).

The set of criteria proposed here also highlights the importance of specifying the implications of a piece of research in an actionable manner. In many cases, the results of the study mark the highpoint of the article, while the implications are addressed in a perfunctory way, sometimes noting only that firms should pay attention to the studied issue. Similarly, research implications are often formulated only as a list of potential research topics, or confined to issues arising from the study's limitations. This is a missed opportunity to achieve higher impact. The guidelines in Table 2 invite authors and reviewers to ask what new research the findings might inspire and how they might guide the use or development of methods, measures, literature, nomological networks, and research frameworks. As a further step, authors might try to envisage how their findings could be used by researchers beyond their disciplinary silo. Sufficiently abstracted and parsimonious findings could be accessible also for researchers who are unfamiliar with the domain's concepts and jargon.

\section{Conclusion}

This article represents a first step toward developing a set of criteria for evaluating and enhancing a research publication's impact potential. This endeavor is especially important for social science disciplines like marketing, where research impact is often indirect and difficult to prove (cf. Muhonen \& Tellmann, 2021). Our central argument is that a publication will have high impact potential if it is likely to promote significant change in how important stakeholders understand or behave in relation to a relevant matter and if it offers simple and clear findings that can be translated into actionable implications, making its message accessible. By operationalizing these drivers as a set of criteria, we provide a concrete toolbox for assessing and enhancing a manuscript's impact potential. At present, measures to enhance an article's impact potential, or to evaluate it during the review process, tend to exist only as tacit knowledge. During the review process, the authors bear the burden of proof and must present compelling arguments in support of their manuscript's potential to impact external audiences (Shugan, 2003). Equally, while journal reviewers may be able to judge a manuscript's methodological or conceptual robustness, its future impact is often difficult to evaluate prior to publication. To that extent, the proposed criteria can be of value to authors, reviewers, and research supervisors.

Importantly, the present article does not downplay the importance of rigor but suggests the need for a balancing impact perspective. Sufficient rigor should be considered a hygiene factor for delivering trustworthy results, but not the main selling point of the article. As Yadav (2018) noted, knowledge development approaches in the marketing discipline have become increasingly scripted, constituting a straitjacket that may hamper impactful research. Authors should therefore explain why their chosen methodology is adequate for addressing the target problem and how impact would be undermined by a more rigid approach. Authors should also argue against the narrow view that rigor relates only to the application of sophisticated and complicated quantitative methodologies (cf. Houston, 2019).

In terms of future research effort on the topic of impact, we invite scholars to further develop the proposed criteria. The goal is that in the future, authors will more fully assess and explicate their efforts to improve the impact potential of their work. If marketing academics genuinely believe that impact matters, it should be afforded the same status as methodological rigor in academic publications. We hope that scholars will use, advance, and promote these criteria in helping to establish impact evaluation as an institutionalized practice.

Funding Open Access funding provided by University of Turku (UTU) including Turku University Central Hospital.

\section{Declarations}

\section{Conflicts of interests None.}

Open Access This article is licensed under a Creative Commons Attribution 4.0 International License, which permits use, sharing, adaptation, distribution and reproduction in any medium or format, as long as you give appropriate credit to the original author(s) and the source, provide a link to the Creative Commons licence, and indicate if changes were made. The images or other third party material in this article are included in the article's Creative Commons licence, unless indicated otherwise in a credit line to the material. If material is not included in the article's Creative Commons licence and your intended use is not permitted by statutory regulation or exceeds the permitted use, you will need to obtain permission directly from the copyright holder. To view a copy of this licence, visit http://creativecommons.org/licenses/by/4.0/. 


\section{References}

Aguinis, H., Shapiro, D. L., Antonacopoulou, E. P., \& Cummings, T. G. (2014). Scholarly impact: A pluralist conceptualization. Academy of Management Learning \& Education, 13(4), 623-639.

Alvesson, M., \& Sandberg, J. (2011). Generating research questions through problematization. Academy of Management Review, 36(2), 247-271.

Antonetti, P., \& Maklan, S. (2014). Feelings that make a difference: How guilt and pride convince consumers of the effectiveness of sustainable consumption choices. Journal of Business Ethics, 124(1), 117-134.

Aspara, J., \& Tikkanen, H. (2017). Why do public policy-makers ignore marketing and consumer research? A case study of policy-making for alcohol advertising. Consumption Markets \& Culture, 20(1), 12-34.

Backhaus, K., Lügger, K., \& Koch, M. (2011). The structure and evolution of business-to-business marketing: A citation and co-citation analysis. Industrial Marketing Management, 40(6), 940-951.

Baraldi, E., La Rocca, A., \& Perna, A. (2014). Good for science, but which implications for business? An analysis of the managerial implications in high-impact B2B marketing articles published between 2003 and 2012. Journal of Business \& Industrial Marketing., 29(7/8), 574-592.

Barnett, L. (2005). The universe and Dr. Einstein. Dover.

Baumgartner, H., \& Pieters, R. (2003). The structural influence of marketing journals: A citation analysis of the discipline and its subareas over time. Journal of Marketing, 67, 123-139.

Birkinshaw, J., Lecuona, R., \& Barwise, P. (2016). The relevance gap in business school research: Which academic papers are cited in managerial bridge journals? Academy of Management Learning \& Education, 15(4), 686-702.

Blocker, C. P., Ruth, J. A., Sridharan, S., Beckwith, C., Ekici, A., Goudie-Hutton, M., \& Varman, R. (2013). Understanding poverty and promoting poverty alleviation through transformative consumer research. Journal of Business Research, 66(8), 1195-1202.

Bolton, R. N. (2020). First steps to creating high impact theory in marketing. AMS Review, 10(3), 172-178.

Brodie, R. J., Hollebeek, L. D., Jurić, B., \& Ilić, A. (2011). Customer engagement: Conceptual domain, fundamental propositions, and implications for research. Journal of Service Research, 14(3), 252-271.

Brown, S. W., Webster, F. E., Steenkamp, J. B. E., Wilkie, W. L., Sheth, J. N., Sisodia, R. S., \& Bauerly, R. J. (2005). Marketing renaissance: Opportunities and imperatives for improving marketing thought, practice, and infrastructure. Journal of Marketing, 69(4), 1-25.

Clark, T., Key, T. M., Hodis, M., \& Rajaratnam, D. (2014). The intellectual ecology of mainstream marketing research: An inquiry into the place of marketing in the family of business disciplines. Journal of the Academy of Marketing Science, 42(3), 223-241.

Davis, B., \& Ozanne, J. L. (2019). Measuring the impact of transformative consumer research: The relational engagement approach as a promising avenue. Journal of Business Research, 100, 311-318.

Day, G. S. (1992). Marketing's contribution to the strategy dialogue. Journal of the Academy of Marketing Science, 20(4), 323-329.

Flesch, R. (1948). A new readability yardstick. Journal of Applied Psychology, 32(3), 221-233.

Gonsalves, C., Ludwig, S., de Ruyter, K., \& Humphreys, A. (2021). Writing for impact in service research. Journal of Service Research, 24(4), 480-499.

Gunning, R. (1952). The technique of clear writing. Macmillan.

Hauser, J. R. (2017). Phenomena, theory, application, data, and methods all have impact. Journal of the Academy of Marketing Science, 45(1), 7-9.

Hoffman, D. L., \& Holbrook, M. B. (1993). The intellectual structure of consumer research: A bibliometric study of author cocitations in the first 15 years of the Journal of Consumer Research. Journal of Consumer Research, 19(4), 505-517.

Houston, M. (2019). Four facets of rigor. Journal of the Academy of Marketing Science, 47, 570-573.

Key, T. M., Clark, T., Ferrell, O. C., Stewart, D. W., \& Pitt, L. (2020). Marketing's theoretical and conceptual value proposition: Opportunities to address marketing's influence. AMS Review, 10(3), 151-167.

Kohli, A. K., \& Haenlein, M. (2021). Factors affecting the study of important marketing issues: Implications and recommendations. International Journal of Research in Marketing, 38(1), 1-11.

Kohli, A. K., \& Jaworski, B. J. (1990). Market orientation: The construct, research propositions, and managerial implications. Journal of Marketing, 54(2), 1-18.

Krasnikov, A., \& Jayachandran, S. (2008). The relative impact of marketing, research-and-development, and operations capabilities on firm performance. Journal of Marketing, 72(4), 1-11.

Lange, D., \& Pfarrer, M. D. (2017). Editors' comments: Sense and structure-The core building blocks of an AMR article. Academy of Management Review, 42(3), 407-416.

Leeflang, P. S., \& Wittink, D. R. (2000). Building models for marketing decisions: Past, present and future. International Journal of Research in Marketing, 17(2-3), 105-126.

Lehmann, D. R., McAlister, L., \& Staelin, R. (2011). Sophistication in research in marketing. Journal of Marketing, 75(4), 155-165.

Li, L. P., Fehrer, J. A., Brodie, R. J., \& Juric, B. (2021). Trajectories of influential conceptual articles in service research. Journal of Service Management, 32(5), 645-672.

Lilien, G. L., Roberts, J. H., \& Shankar, V. (2013). Effective marketing science applications: Insights from the ISMS-MSI practice prize finalist papers and projects. Marketing Science, 32(2), 229-245.

Lindgreen, A., Di Benedetto, C. A., Brodie, R. J., Fehrer, J., \& Van der Borgh, M. (2020). How to get great research cited. Industrial Marketing Management, 89, A1-A7.

MacInnis, D. J. (2011). A framework for conceptual contributions in marketing. Journal of Marketing, 75(4), 136-154.

MacInnis, D. J., Morwitz, V. G., Botti, S., Hoffman, D. L., Kozinets, R. V., Lehmann, D., \& Pechmann, C. (2020). Creating boundarybreaking, marketing-relevant consumer research. Journal of Marketing, 84(2), 1-23.

Makadok, R., Burton, R., \& Barney, J. (2018). A practical guide for making theory contributions in strategic management. Strategic Management Journal, 39, 1530-1545.

Moorman, C., van Heerde, H. J., Moreau, C. P., \& Palmatier, R. W. (2018). JM as a marketplace of ideas. Journal of Marketing, 83(1), $1-7$.

Moorman, C., van Heerde, H. J., Moreau, C. P., \& Palmatier, R. W. (2019). Challenging the boundaries of marketing. Journal of Marketing, 83(5), 1-4.

Morton, S. (2015). Progressing research impact assessment: A 'contributions' approach. Research Evaluation, 24(4), 405-419.

Muhonen, R., \& Tellmann, S. (2021). Challenges of reporting societal impacts for research evaluation purposes - case of sociology. In T.C.E. Engels \& E. Kulczycki (Eds.), Handbook on research assessment in the social sciences. Edward Elgar Publishing.

Nath, P., \& Mahajan, V. (2011). Marketing in the C-suite: A study of chief marketing officer power in firms' top management teams. Journal of Marketing, 75(1), 60-77.

Nelson, M. R., Ham, C. D., \& Ahn, R. (2017). Knowledge flows between advertising and other disciplines: A social exchange perspective. Journal of Advertising, 46(2), 309-332.

Penfield, T., Baker, M. J., Scoble, R., \& Wykes, M. C. (2014). Assessment, evaluations, and definitions of research impact: A review. Research Evaluation, 23(1), 21-32.

Reale, E., Avramov, D., Canhial, K., Donovan, C., Flecha, R., Holm, P., \& Van Horik, R. (2018). A review of literature on evaluating 
the scientific, social and political impact of social sciences and humanities research. Research Evaluation, 27(4), 298-308.

Reibstein, D. J., Day, G., \& Wind, J. (2009). Guest editorial: Is marketing academia losing its way? Journal of Marketing, 73(4), 1-3.

Roberts, J. H., Kayande, U., \& Stremersch, S. (2014). From academic research to marketing practice: Exploring the marketing science value chain. International Journal of Research in Marketing, 31(2), 127-140.

Sandberg, J., \& Alvesson, M. (2011). Ways of constructing research questions: Gap-spotting or problematization? Organization, 18(1), $23-44$.

Shugan, S. M. (2003). Defining interesting research problems. Marketing Science, 22(1), 1-15.

Smith, D. C. (2003). The importance and challenge of being interesting. Journal of the Academy of Marketing Science, 31(3), 319-322.

Srinivasan, S., \& Hanssens, D. M. (2009). Marketing and firm value: Metrics, methods, findings, and future directions. Journal of Marketing Research, 46(3), 293-312.

Sternberg, R. J., \& Gordeeva, T. (1996). The anatomy of impact: What makes an article influential? Psychological Science, 7(2), 69-75.

Stremersch, S. (2021). Commentary on Kohli \& Haenlein: The study of important marketing issues: Reflections. International Journal of Research in Marketing, 38(1), 12-17.

Stremersch, S., Verniers, I., \& Verhoef, P. C. (2007). The quest for citations: Drivers of article impact. Journal of Marketing, 71(3), 171-193.
Tellis, G. J. (2017). Interesting and impactful research: On phenomena, theory, and writing. Journal of the Academy of Marketing Science, $45(1), 1-6$.

Vargo, S. L., \& Koskela-Huotari, K. (2020). Advancing conceptual-only articles in marketing. AMS Review, 10(1-2), 1-5.

Vargo, S. L., \& Lusch, R. F. (2016). Institutions and axioms: An extension and update of service-dominant logic. Journal of the Academy of Marketing Science, 44(1), 5-23.

Warren, N. L., Farmer, M., Gu, T., \& Warren, C. (2021). Marketing ideas: How to write research articles that readers understand and cite. Journal of Marketing, 85(5), 42-57.

Yadav, M. S. (2018). Making emerging phenomena a research priority. Journal of the Academy of Marketing Science, 46(3), 361-365.

Yadav, M. S. (2010). The decline of conceptual articles and implications for knowledge development. Journal of Marketing, 74(1), 1-19.

Zeithaml, V. A., Jaworski, B. J., Kohli, A. K., Tuli, K. R., Ulaga, W., $\&$ Zaltman, G. (2020). A theories-in-use approach to building marketing theory. Journal of Marketing, 84(1), 32-51.

Publisher's Note Springer Nature remains neutral with regard to jurisdictional claims in published maps and institutional affiliations. 